\title{
Intracellular amyloid-like deposits contain unprocessed pro-islet amyloid polypeptide (prolAPP) in beta cells of transgenic mice overexpressing the gene for human IAPP and transplanted human islets
}

Received: 23 October 2005 / Accepted: 23 December 2005 / Published online: 29 March 2006

(C) Springer-Verlag 2006

\begin{abstract}
Aims/hypothesis: Islet amyloid is a frequent finding in the islets of Langerhans of individuals with type 2 diabetes. The main amyloid constituent is the beta cellderived polypeptide hormone islet amyloid polypeptide (IAPP). In general, amyloid refers to an extracellular deposit of a congophilic material, but intracellular amyloid is seen in some beta cells of transgenic mice expressing the gene for human IAPP and in human islets transplanted into nude mice. The aim of this study was to immunohistochemically characterise the intracellular amyloid. Methods: Antisera against the $\mathrm{N}$ - and C-terminal processing sites of proIAPP (which were therefore specific for proIAPP), the C-terminal flanking peptide and mature IAPP were used for immunoelectron microscopy. Results: Fibrillar aggregates were seen in the halo region of the secretory granules in some beta cells in human IAPP transgenic mice. These aggregates were labelled with proIAPP-specific antisera. Also, proIAPP reactivity was more widespread in the intracellular amyloid-like aggregates in beta cells of transgenic mice than in human islet transplants, in which the intracellular amyloid-like deposits were larger, but the proIAPP labelling was restricted to small spots within the amyloid deposits. Conclusions/ interpretation: We suggest that proIAPP forms the first amyloid fibrils and that this can occur already in the
\end{abstract}

\footnotetext{
J. F. Paulsson · G. T. Westermark ( $\bowtie)$

Division of Cell Biology, Diabetes Research Centre,

Linköping University,

Linköping, Sweden

e-mail: Gunwe@ibk.liu.se

Tel.: +46-13-223906

Fax: +46-13-224149

\section{A. Andersson}

Department of Medical Cell Biology, Uppsala University,

Uppsala, Sweden

P. Westermark

Department of Genetics and Pathology, Uppsala University,

Uppsala, Sweden
}

secretory granules of the beta cells. The proIAPP-derived fibrils can act as seed for further amyloid formation, now made up by IAPP. The observed difference between human islet transplants and human IAPP transgenic animals may reflect differences in stages of amyloid development.

Keywords Amyloid · Beta cell granule - Electron microscopy - Human islets of Langerhans - Human islet transplant · IAPP · Intracellular amyloid · Islet amyloid polypeptide · ProIAPP - Pro-islet amyloid polypeptide . Type 2 diabetes

Abbreviations CPE: carboxypeptidase E - IAPP: islet amyloid polypeptide $\cdot$ PAM: peptidylglycine alphaamidating monooxygenase $\cdot$ PC: prohormone convertase PS: phosphatidylserine $\cdot$ TBS: tris-buffered saline

\section{Introduction}

Islet amyloid is strongly associated with type 2 diabetes and is present in a great majority of diabetic individuals post mortem [1]. In 1986, islet amyloid polypeptide (IAPP), a peptide 37 amino acids in length, was identified as the main component of islet amyloid [2]. IAPP is produced as a precursor peptide, proIAPP, consisting of 67 residues. ProIAPP is enzymatically processed by the converting enzymes prohormone convertase 2 and $1 / 3$ (PC2 and PC1/3) [3], which cleave proIAPP at the N- and the C-terminus, respectively, at di-basic amino acids [4-6]. This results in the removal of an 11-residue N-terminal flanking peptide and a 16-residue C-terminal flanking peptide. Following this reaction, at the $\mathrm{C}$-terminus, carboxypeptidase E removes the lysine and arginine residues, leaving a glycine residue for peptidylglycine alpha-amidating monooxygenase (PAM) to amidate the peptide [7-10]. Formation of a disulphide bridge between cysteine residues 2 and 7 is required for full biological activity of mature IAPP [10]. 
Insulin and IAPP are stored in the beta cell and are secreted upon stimulation [11]. The same prohormone convertases process proinsulin into insulin. $\mathrm{PC} 1 / 3$ cleaves proinsulin between the B-chain and the C-peptide, giving rise to a processing intermediate termed des-31,32 proinsulin, whereas $\mathrm{PC} 2$ cleaves proinsulin between the A-chain and the C-peptide [12]. Secretion of proinsulin and the processing intermediate des-31,32 is elevated in patients with type 2 diabetes $[13,14]$. Since insulin and IAPP are processed by the same enzymes and are released simultaneously, plasma levels of proIAPP would also be expected to be raised in these patients.

It is generally assumed that a greater demand for insulin as a result of peripheral insulin resistance forces beta cells to produce proinsulin/proIAPP at a faster rate than the converting enzymes can process these prohormones [15, 16]. However, studies have shown that chronically high levels of circulating NEFAs reduce activation of the prohormone convertases, resulting in aberrant processing of the prohormones [17].

Amyloid can create disturbances in the organs via different mechanisms, either by induction of apoptosis or by physical obstruction (when large amounts of amyloid are present). Protein aggregation into amyloid fibrils is preceded by the formation of oligomers that are toxic to the cell (so-called 'protofibrils') [18]. These fibrillar intermediates are believed to exert the toxic activity associated with amyloid, and cause apoptosis by incorporation into the plasma membrane, where they form pore-like structures that increase the permeability of the membrane, allowing ions to cross the lipid layer [19-22].

Amyloid has classically been described as an extracellular deposit, but several reports indicate that the initial amyloid formation might occur intracellularly, at least for some forms. We have recently reported that expression of the cDNA corresponding to human proIAPP in GH4 cells, a cell line deficient in $\mathrm{PC} 2$ and $\mathrm{PC} 1 / 3$ and therefore incapable of processing proIAPP into IAPP, results in the formation of intracellular congophilic material [23]. When the same cDNA is expressed in beta TC-6 cells, a cell line possessing both PC2 and PC1/3, no deposition of amyloidlike material occurs. In human insulinomas and, more interestingly, in human islets transplanted under the renal capsule of nude mice, intracellular accumulations of congophilic amyloid-like deposits have been detected $[24,25]$. Intracellular amyloid-like aggregates have also been reported to occur in transgenic mice expressing the gene for human IAPP [26-28]. In general, these mice had either been treated with a combination of growth hormone and dexamethasone or fed a diet high in fat.

This study is an immunohistochemical characterisation at the ultrastructural level of the intracellular amyloid-like aggregates present in transgenic mice expressing the gene for human IAPP and in human islets transplanted into the renal subcapsular space of nude mice. For this, several antibodies specific for different epitopes of human proIAPP were used.

\section{Materials and methods}

Animals and diet Male mice $(n=8)$ expressing the gene for human IAPP but not mouse IAPP (+hIAPP/-mIAPP) were caged individually with free access to water, standard chow (Lactamin; Vadstena, Sweden) and lard (Ellco Food, Kävlinge, Sweden) during a 12/12 h light/dark cycle. This animal model has previously been described in detail [26]. A group of eight control animals of the same strain were housed under the same conditions, with the exception of access to lard. All experiments were approved by the ethics committee of Linköping University. Animals were fed the diets for 11 months. At the end of the study period, the blood glucose level was determined after $16 \mathrm{~h}$ fasting in animals fed the high-fat diet $(5.1 \pm 1.2 \mathrm{mmol} / \mathrm{l})$ and in control animals fed the standard diet $(4.4 \pm 0.5 \mathrm{mmol} / \mathrm{l})$ $(p<0.1)$. Thereafter, the animals were killed and pancreases were fixed for electron microscopy in $2 \%$ paraformaldehyde with $0.25 \%$ glutaraldehyde in PBS (137 mmol/l, $\mathrm{NaCl}, 2.7 \mathrm{mmol} / \mathrm{l} \mathrm{KCl}, 4.3 \mathrm{mmol} / \mathrm{l}$ $\mathrm{Na}_{2} \mathrm{HPO}_{4}, 1.4 \mathrm{mmol} / 1 \mathrm{KH}_{2} \mathrm{PO}_{4}, \mathrm{pH}$ 7.4) for $24 \mathrm{~h}$. Parts of the tissues were post-fixed in $\mathrm{OsO}_{4}$ prior to dehydration and embedding in Epon (Ladd Research Industries, Burlington, VT, USA). For light microscopy, specimens were fixed in $4 \%$ of neutral buffered formaldehyde solution and embedded in paraffin.

Human islets transplanted to nude mice Methods pertaining to the transplantation of under the renal capsule of non-diabetic nude mice have previously been described in detail $[25,29]$. Prior to the transplantation procedure, the islets had been isolated and cultured in vitro for a short period of time. After 2-4 weeks, transplants were removed, fixed in $2.5 \%$ glutaraldehyde in PBS for $6 \mathrm{~h}$, postfixed in $\mathrm{OsO}_{4}$, dehydrated and embedded in Epon [30].

Quantification of cells with intracellular amyloid The percentage of cells with intracellular amyloid was determined after Congo red staining for four of the +hIAPP/-mIAPP mice fed a high-fat diet. Islets were analysed for the presence of amyloid in five sections from each animal. Cells were counted in amyloid-containing islets and only cells with a nucleus surrounded by cytoplasm were included.

Apoptosis studies Paraffin-embedded tissue was cut into $8-\mu \mathrm{m}$ sections, and dried on slides (Plus slides; Histolab, Gothenburg, Sweden). Antigenic retrieval was performed by heat treatment in $10 \mathrm{mmol} / \mathrm{l}$ citric acid buffer, $\mathrm{pH} 6.0$. Sections were placed in a container with $500 \mathrm{ml}$ buffer, and autoclaved at $121^{\circ} \mathrm{C}$ for $20 \mathrm{~min}$. The sections were allowed to adjust to room temperature and endogenous peroxidase was blocked by incubation in $0.3 \% \mathrm{H}_{2} \mathrm{O}_{2}$ in Tris-buffered saline (TBS; $50 \mathrm{mmol} / \mathrm{l}$ Tris- $\mathrm{HCl}$, $150 \mathrm{mmol} / \mathrm{l} \mathrm{NaCl}, \mathrm{pH}$ 7.6). Sections were rinsed three times in TBS and incubated with M30 monoclonal antibodies (M30 cytoDEATH; Roche, Mannheim, Germany) at 1:100 dilution in TBS overnight. The monoclonal M30 recognises a neo-epitope in cytokeratin 18 
(CK-18) that becomes accessible upon caspase cleavage during early apoptosis. Sections were washed three times in TBS and incubated in secondary antibody, swine antimouse conjugated with HRP/Envision (DakoCytomation, Glostrup, Denmark). The peroxidase was visualised with 3,3' diaminobenzidine tetrahydrochloride (DAB). After immunolabelling, sections were stained for amyloid with Congo red [31]. Slides were counterstained with Mayer's nuclear stain, rinsed in absolute alcohol and xylene, and mounted with Mountex (Histolab). The presence of amyloid was established using a Nikon Eclipse E800 (Nikon, Tokyo, Japan) equipped with filters for wavelengths of $560 \mathrm{~nm}$ (excitation) and $590 \mathrm{~nm}$ (emission).

Immunoelectron microscopy Ultra-thin sections were placed on formvar-coated nickel grids. Prior to immunolabelling, antigenic epitopes were retrieved with a hydrous solution of saturated sodium periodate $\left(\mathrm{NaIO}_{4}\right)$ for $10 \mathrm{~min}$. Thereafter, the sections were washed extensively in deionised water and unspecific binding to the tissue was blocked with 3\% BSA in TBS for $30 \mathrm{~min}$. Sections were incubated with polyclonal antisera against IAPP (A110), proIAPP (A169, A165, A142), insulin (DakoCytomation) and C-peptide (A157), as presented in Table 1. Antiserum A157 was raised against a synthetic peptide corresponding to human C-peptide (residues 33-63 of human proinsulin). This antiserum immunolabels beta cells and reacts with $\mathrm{C}$ peptide but not with human insulin when tested in slot blot analysis. An exact description of epitopes for A110, A169, A165 and A142 is shown in Fig. 1. A169 and A165 antibodies are well characterised and they do not recognise IAPP 1-37. A169 binds to a peptide corresponding to residues $1-48$ of proIAPP, while A165 binds to a peptide corresponding to residues $12-67$ of proIAPP. The antisera A169 and A165 do not cross-react with each other's processing site [23]. Antisera were diluted 1:200 in TBS containing $1 \%$ BSA, with the exception of A169, where a dilution of 1:50 was used. Controls included sections treated with antisera absorbed with the respective peptides. Specimens were incubated with the primary antibody overnight and then washed three times in TBS and blocked for $30 \mathrm{~min}$ in $3 \% \mathrm{BSA}$ in TBS. Secondary antibody was goat anti-rabbit antibody conjugated with gold particles $(10 \mathrm{~nm}$ diameter; BB International, Cardiff, UK) at a dilution of $1: 200$ in 1\% BSA in TBS. Insulin antibody was detected with Protein A-10-nm gold (BB International) diluted 1:200 with $1 \% \mathrm{BSA}$ in TBS.
Sections were contrasted with $2 \%$ uranyl acetate in $50 \%$ ethanol for $10 \mathrm{~min}$ and in Reynold's lead citrate solution (120 mmol/1 sodium citrate, $25 \mathrm{mmol} / 1$ lead citrate, $\mathrm{pH} 12)$ for $90 \mathrm{~s}$. The material was studied at $100 \mathrm{kV}$ in a Jeol 1230 electron microscope (Jeol, Akishima, Tokyo, Japan). Electron micrographs were taken with a Gatan multiscan camera model 791 with Gatan digital micrograph software version 3.6.4 (Gatan, Pleasanton, CA, USA).

\section{Results}

Quantification of cells with intracellular amyloid Of 330 islets identified in the pancreatic specimens from +hIAPP/ -mIAPP mice, 24 contained intracellular amyloid. A total of 8721 cells from the amyloid-containing islets were counted, and the number of cells filled with amyloid in each islet varied from one to four.

Apoptosis studies Cellular immunoreactivity with the antibody against the cytokeratin-18-derived epitope was present in islets from + hIAPP/-mIAPP mice fed a high-fat diet (Fig. 2a) and such cells also stained with Congo red amyloid stain (Fig. 2b). Co-localisation of intracellular amyloid and the apoptosis marker is evident on merged pictures (Fig. 2c).

Immunoelectron microscopy of cells from +hIAPP/ - mIAPP mice In the islets of +hIAPP/-mIAPP mice fed a high-fat diet for 11 months, there was an altered granule morphology in $5-10 \%$ of the beta cells. Thus, thread-like structures resembling amyloid fibrils were found in the halo region of the granules (Figs. 3a,b,e,f and $4 a-d$ ). In sections treated with osmium, which binds to membranes, granule membranes were seen surrounding the fibrillar structures. When these fibrillar structures were immunohistochemically characterised, reactivity with antisera against IAPP (Fig. 3a,b) and the $\mathrm{N}$ - and $\mathrm{C}$-terminal processing sites of proIAPP (Fig. 4a,b) was noted. Intragranular fibrils also showed reactivity with antiserum against the C-terminus of proIAPP (Fig. 4c). Immunolabelling indicated that intragranular fibrils did not contain insulin (Fig. 3e,f) or C-peptide (Fig. 4d). This labelling pattern indicates that the intragranular fibrils consist of unprocessed proIAPP. The group of control animals on a standard diet displayed normal granule morphology; there were no intragranular fibrils (Fig. 3c,d).

Table 1 Antisera used in immunolabelling experiments

\begin{tabular}{lllll}
\hline Name & Species & Antigen & Dilution & Source \\
\hline A 110 & Rabbit & Mouse IAPP 1-37 & $1: 200$ & Authors \\
A 169 & Rabbit & N-terminal processing site & $1: 50$ & Authors \\
A 165 & Rabbit & C-terminal processing site & $1: 200$ & Authors \\
A 142 & Rabbit & C-terminal flanking peptide & $1: 200$ & Authors \\
Insulin & Guinea pig & Insulin & $1: 200$ & Dako \\
A 157 & Rabbit & C-peptide & $1: 200$ & Authors \\
\hline
\end{tabular}




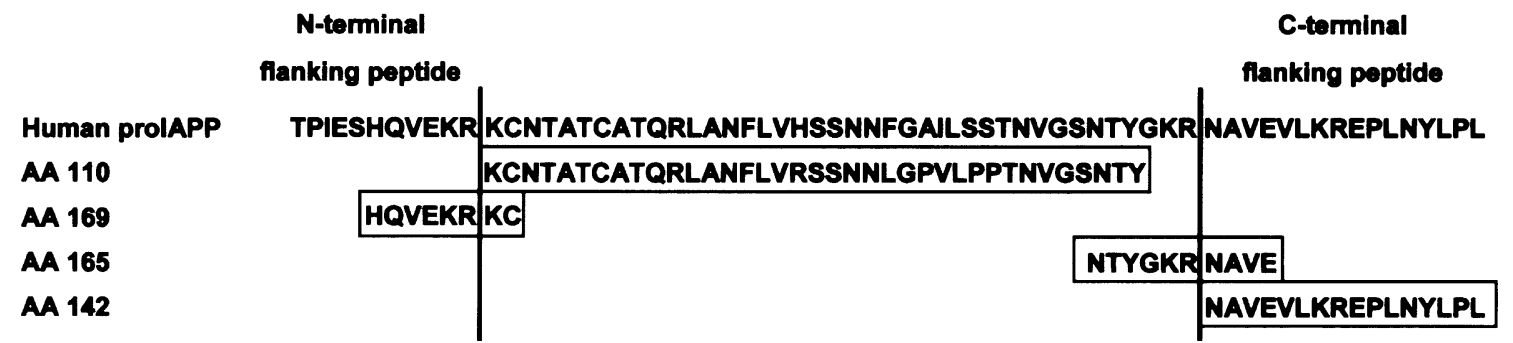

Fig. 1 The amino acid sequence of human proIAPP outlined using single letter code. The $\mathrm{PC} 2$ processing site at residues $\mathrm{K}^{10} \mathrm{R}^{11}$ and the $\mathrm{PC} 1 / 3$ processing site at residues $\mathrm{L}^{50} \mathrm{~K}^{51}$ are indicated by the vertical lines. Epitopes for the different proIAPP antisera are shown

In control mice, immunolabelling for IAPP was restricted to the halo region of the secretory granules (data not shown).

Larger amyloid-like aggregates were found in some beta cells of the +hIAPP/-mIAPP mice fed a high-fat diet (Figs. 5a and 6a-d). These deposits were located close to the nucleus and had a fibrillar appearance. In sections from the osmium-treated material, a surrounding membrane was visible in some areas, but the amyloid aggregates were only partially enclosed (Fig. 5a, high magnification). Immunolabelling revealed the presence of IAPP (Figs. 5a and 6a), both $\mathrm{N}$ and $\mathrm{C}$-terminal processing sites (Fig. 6b,c), and the C-terminus of proIAPP (Fig. 6d) in the intracellular amyloid-like mass. Note that secretory granules appeared docked to the fibrillar mass. Immunolabelling did not detect insulin or C-peptide in these aggregates (data not shown). Beta cells in which most of the cytoplasm had been replaced with amyloid-like mass were also identified. The nuclei of these cells were pyknotic and proIAPP reactivity was found within the amyloid-like material.

Immunoelectron microscopy of human islets In human islet implants, fibrillar deposits with amyloid resemblance were found intracellularly in the beta cells. Immunolabelling indicated the presence IAPP (Figs. 5b and 7a). Rounded in the boxes beneath the sequence. Antiserum 110 was raised against mouse IAPP $1-37$, and this antiserum cross-reacts fully with human IAPP

fibrillar structures the size of secretory granules were identified in the periphery of the amyloid-like masses (Fig. 7a-d, right panel). These structures showed reactivity with antisera against IAPP (Figs. $5 \mathrm{~b}$ and $7 \mathrm{a}$, right panel), $\mathrm{N}$ and C-terminal processing sites (Fig. 7b,c, right panel) and the $\mathrm{C}$-terminus of proIAPP (Fig. $7 \mathrm{~d}$, right panel). In contrast to the murine cells, no intragranular fibrils were seen. The labelling for the processing sites and for the Cterminal flanking peptide was patchy and not as even as that seen in the murine islets.

\section{Discussion}

Islet amyloid is a common pathological feature of type 2 diabetes and is well characterised, but underlying events triggering amyloidogenic processes are not very well defined. In this study, we have characterised amyloid-like structures in beta cells from +hIAPP/-mIAPP mice and human islet grafts using immunoelectron microscopy. Although the amyloid formation might be at different stages in these two models, the intracellular amyloid-like aggregates containing proIAPP are biochemically similar. Intracellular amyloid has not been reported to occur in pancreases recovered post mortem. However, development of the islet lesion in human diabetes is probably a very
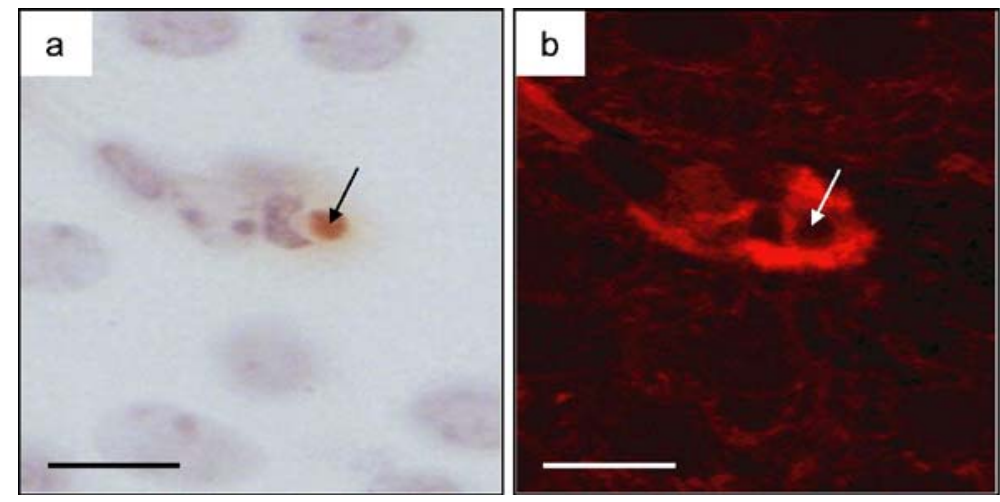

Fig. 2 Immunohistochemistry with M30 cytoDEATH antibodies reactive against a neo-epitope of cytokeratin-18 that occurs during early apoptosis, applied on cells in an islet of Langerhans from a transgenic + hIAPP/-mIAPP mouse fed a high-fat diet. Congo red staining was used for simultaneous detection of amyloid. a Intracellular immunoreactivity is presented as brown deposition indicated by a black arrow. b Amyloid-specific Congo red fluorescence is shown. The white arrow points to the site of cytokeratin-18 reactivity. $\mathbf{c}$ Figures $\mathbf{a}$ and $\mathbf{b}$ are merged and show co-deposition of the apoptosis marker and amyloid intracellularly. Scale bars represent $10 \mu \mathrm{m}$ 
Fig. 3 Electron micrographs of beta cell granules from + hIAPP/ - mIAPP mice. The figure shows granules in animals fed a high-fat diet $(\mathbf{a}, \mathbf{b}, \mathbf{e}, \mathbf{f})$ (intragranular fibrils present) and in control animals $(\mathbf{c}, \mathbf{d})$ are from the control group (no intragranular fibrils are present). Granules shown in a, $\mathbf{c}$ and $\mathbf{e}$ were treated with $\mathrm{OsO}_{4}$ and the membrane surrounding the secretory granules is visible. In $\mathbf{a}$ and $\mathbf{b}$, antiserum A110 reacts with the intragranular fibrils (white arrows). In $\mathbf{c}$ and $\mathbf{d}$ no intragranular fibrils are present. In $\mathbf{e}$ and $\mathbf{f}$, anti-insulin immunoreactivity is restricted to the core region of the secretory granules, and no reactivity is present with the fibrillar material. Scale bars represent $200 \mathrm{~nm}$
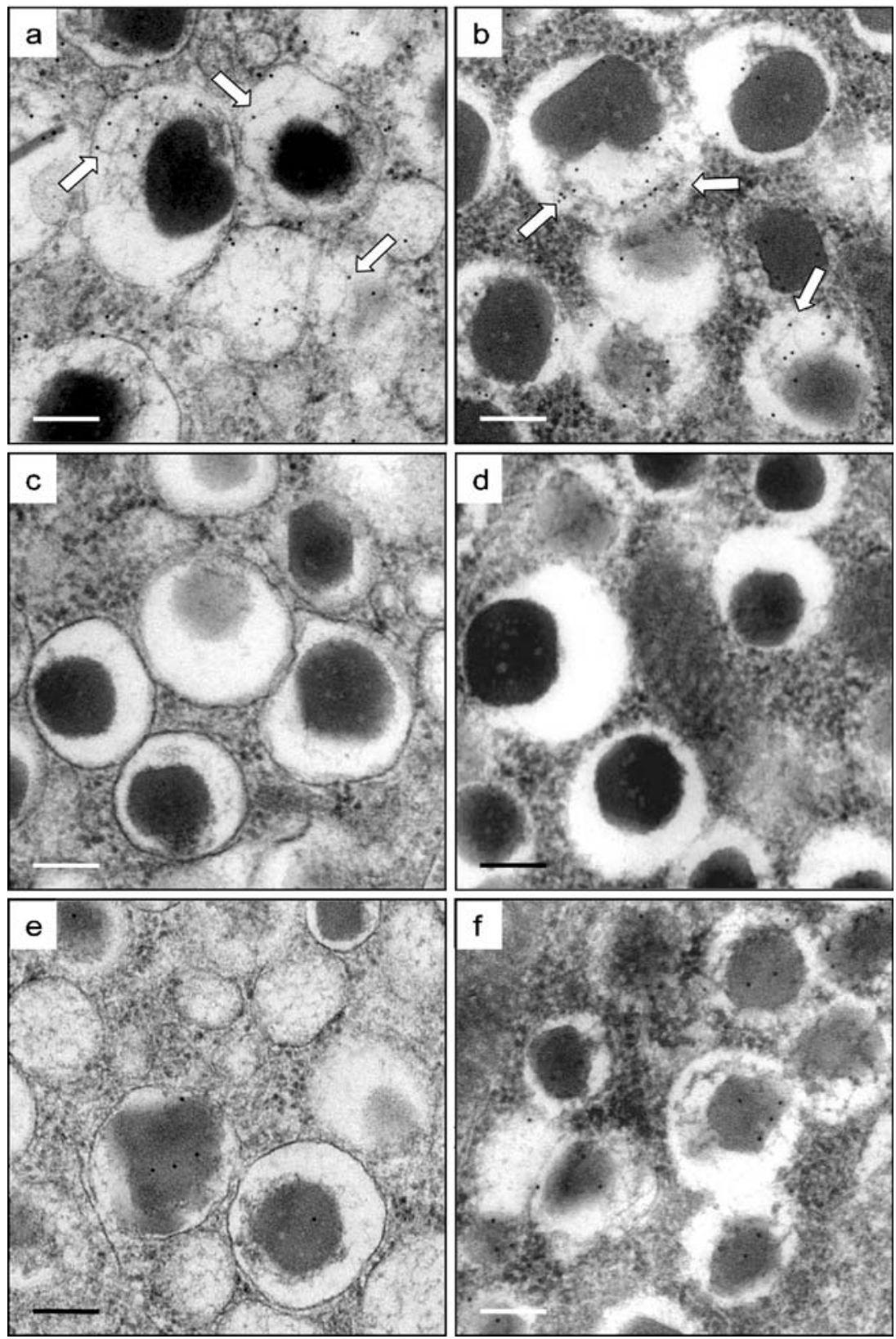

long-lasting process, and intracellular amyloid may occur at an early stage. In addition, autolytic alterations often make detailed cellular analyses difficult.

Amyloid is generally referred to as an extracellular proteinaceous fibrillar substance with certain characteristic properties [32]. We and others have previously found that deposits of amyloid-like material may be found in the cytoplasm of beta cells of human islets transplanted into nude mice [29], in insulinoma tumour cells [24] and in beta cells of + hIAPP/-mIAPP mice [26]. It has also been suggested that these intracellular aggregates may lead to cell death. Formation of any amyloid fibril is a nucleationdependent process, and preformed fibrils may catalyse the conversion of a soluble protein to its fibrillar form. Human IAPP is a highly amyloidogenic peptide, and the release of insoluble intracellular aggregates into the extracellular space (e.g. by cell death) may stimulate the conversion of secreted IAPP. Consequently, elucidation of the initial step in amyloidogenesis, which may be an intracellular event, is particularly important.

In addition to cell death, there is another possible mechanism by which intracellularly formed fibrils may be released into the extracellular space. In beta cells, insulin is located in the core area and IAPP in the halo region close to the lipid bilayer of the enclosed secretory vesicle [33]. When beta cell granules from + hIAPP/-mIAPP mice fed a high-fat diet were morphologically investigated, fibrillar structures resembling amyloid fibrils were identified in the halo region in a large proportion of the islets. We previously described a similar phenomenon when islets of Langerhans from $+\mathrm{hIAPP} /-$ mIAPP mice were cultured in medium containing high levels of NEFAs [34]. 
Fig. 4 Electron micrographs of beta cell granules from + hIAPP/ - mIAPP mice. Figures a, b, c and $\mathbf{d}$ show secretory granules with intragranular fibrils from fibrils are immunolabelled with the antisera A169 (N-terminal processing site) (a), A165 (Cterminal processing site) (b) and A142 (C-terminal flanking peptide) (c). d No reactivity with the fibrillar material is present when antibodies against C-peptide are used. White arrows indicate immunoreactive fibrils. Scale bars represent $200 \mathrm{~nm}$ animals on a high fat diet. The
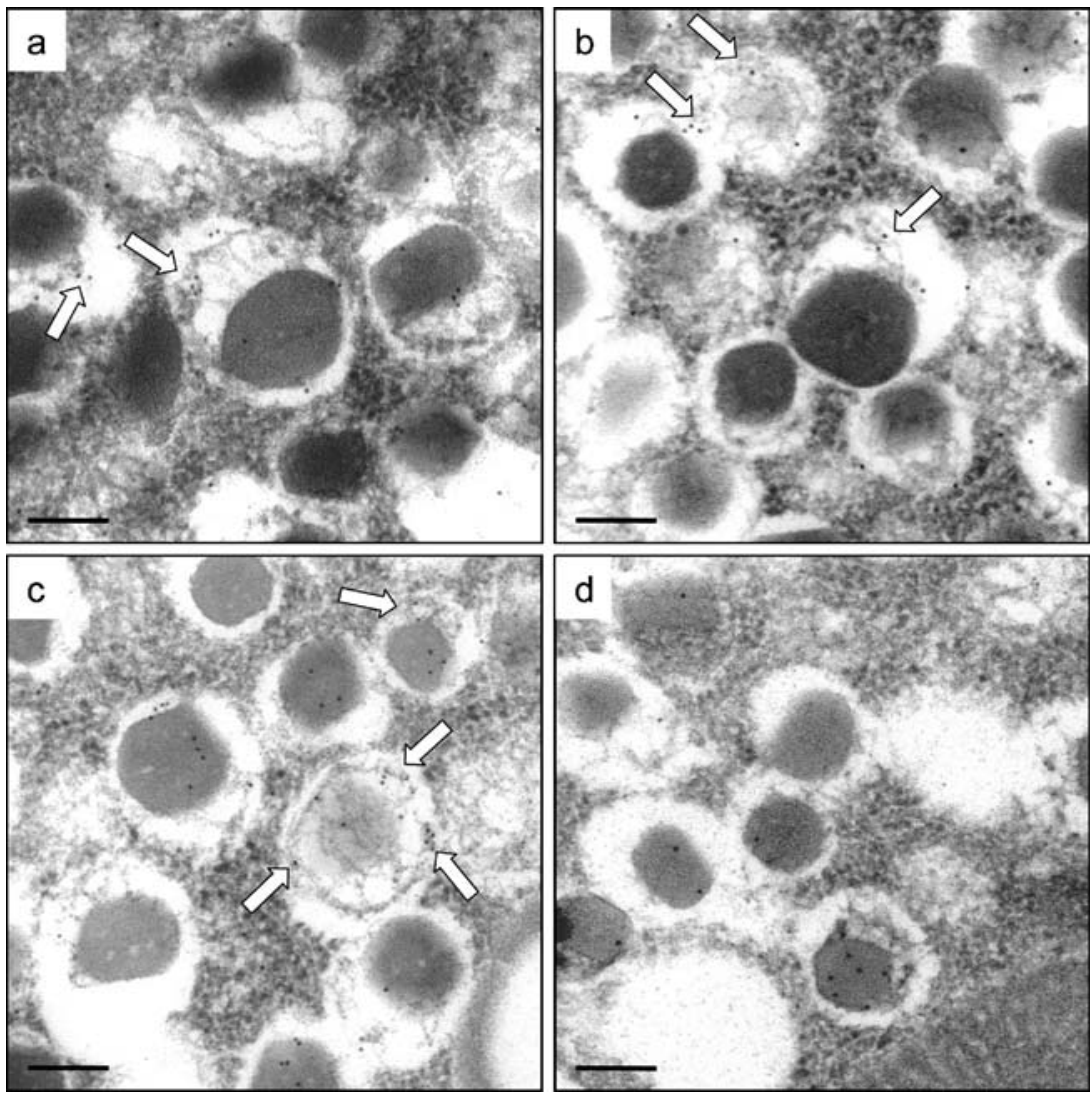

Fig. 5 Electron micrographs of beta cells from +hIAPP/ -mIAPP mice and human islet implants. The square frames indicate the sections shown at higher magnification in the right panel. a A section of $\mathrm{OsO}_{4}$ treated pancreas with intracellular amyloid from a $+\mathrm{hIAPP} /$ -mIAPP mouse fed a high-fat diet. b A section from an $\mathrm{OsO}_{4}$ treated human islet implant with intracellular amyloid. Immunolabelling with A110 shows reactivity with aggregates with a clear fibrillar appearance and these are partly surrounded by membrane. In a, notice the close association between a granule and amyloid-like deposition (thin black arrow). In b, a coherent area of intracellular amyloid deposits $(A)$ is seen. $N$, nucleus; $M$, mitochondria; black arrows, cell membrane; white arrows, border of the intracellular amyloid-like aggregates at higher magnification. Scale bars represent $500 \mathrm{~nm}$
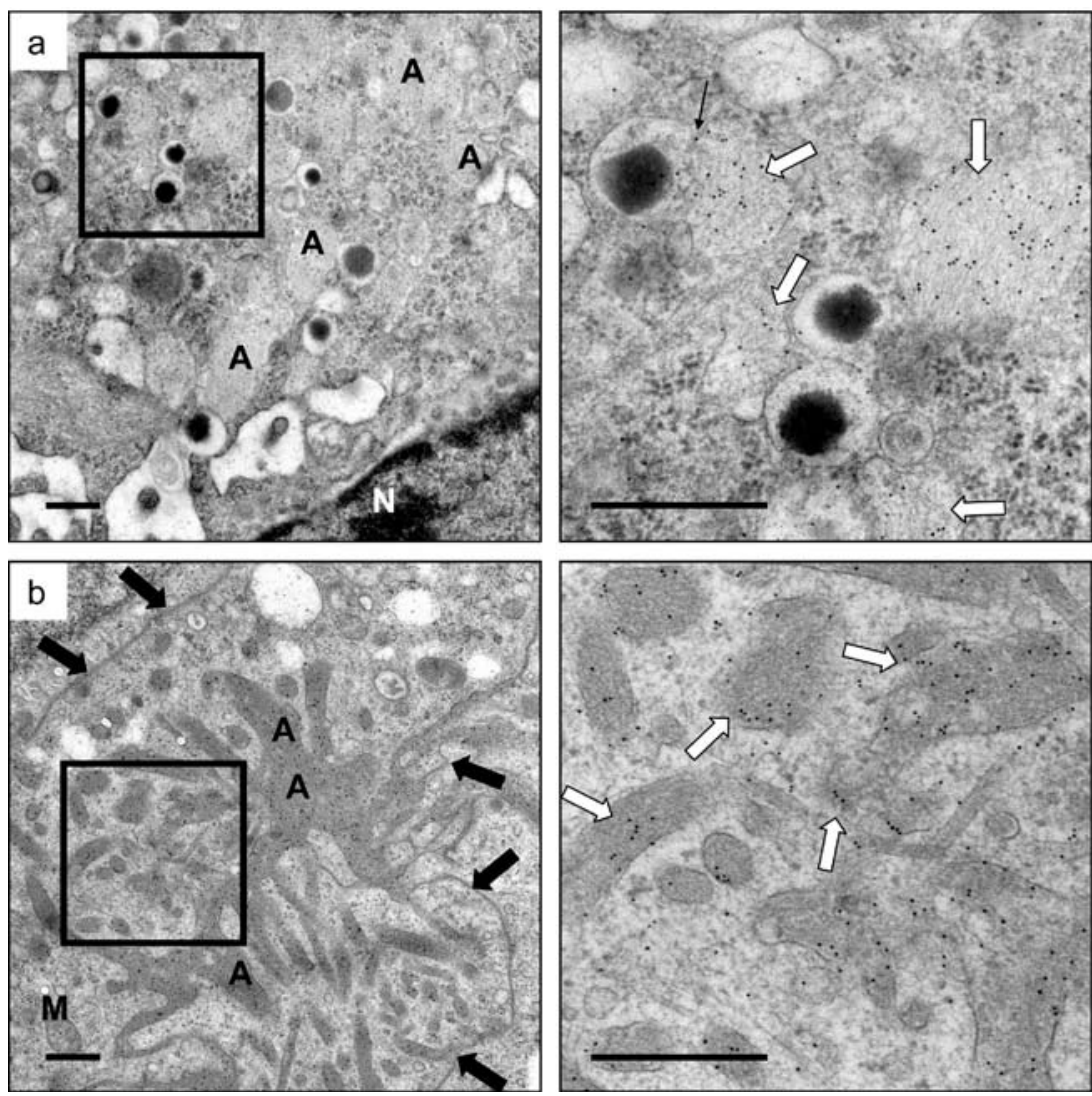
Fig. 6 Electron micrographs of islet beta cells from +hIAPP/ -mIAPP mice fed a diet high in fat. Intracellular amyloid-like aggregates can be seen as grey areas indicated with an $A$, while the cell nuclei are indicated with an $N$. The sections in the square frames are shown at higher magnification in the right panel. The white arrows indicate amyloid. Sections were immunolabelled with antiserum A110 (IAPP) (a), A169 (N-terminal cleavage site) (b), A165 (Cterminal cleavage site) (c) and A142 (C-terminal flanking peptide) (d). The amyloid-like aggregates are labelled by all four antisera. Scale bars represent $500 \mathrm{~nm}$
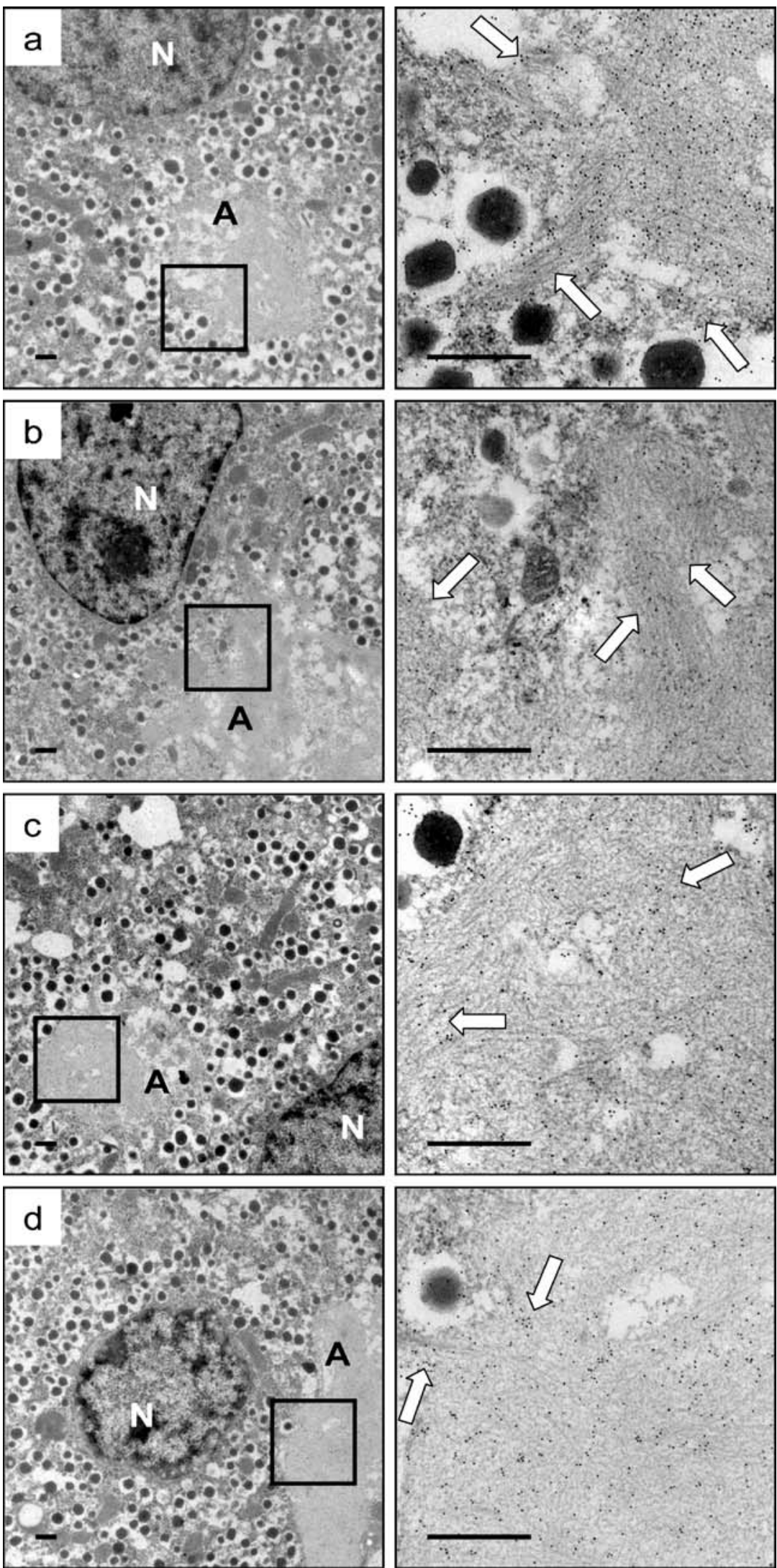
Fig. 7 Electron micrographs of human beta cells originating from islets transplanted under the renal capsule of non-diabetic nude mice. Amyloid-like material is indicated with an $A$ and a cell nucleus is labelled with an $N$. The sections in the square frames are shown at higher magnification in the right panels. Immunoreactivity is indicated by the white arrows. Cells were labelled with A110 (a) are immunolabelled with A169 (b), A165 (c) and A142 (d), respectively. Scale bars represent $500 \mathrm{~nm}$
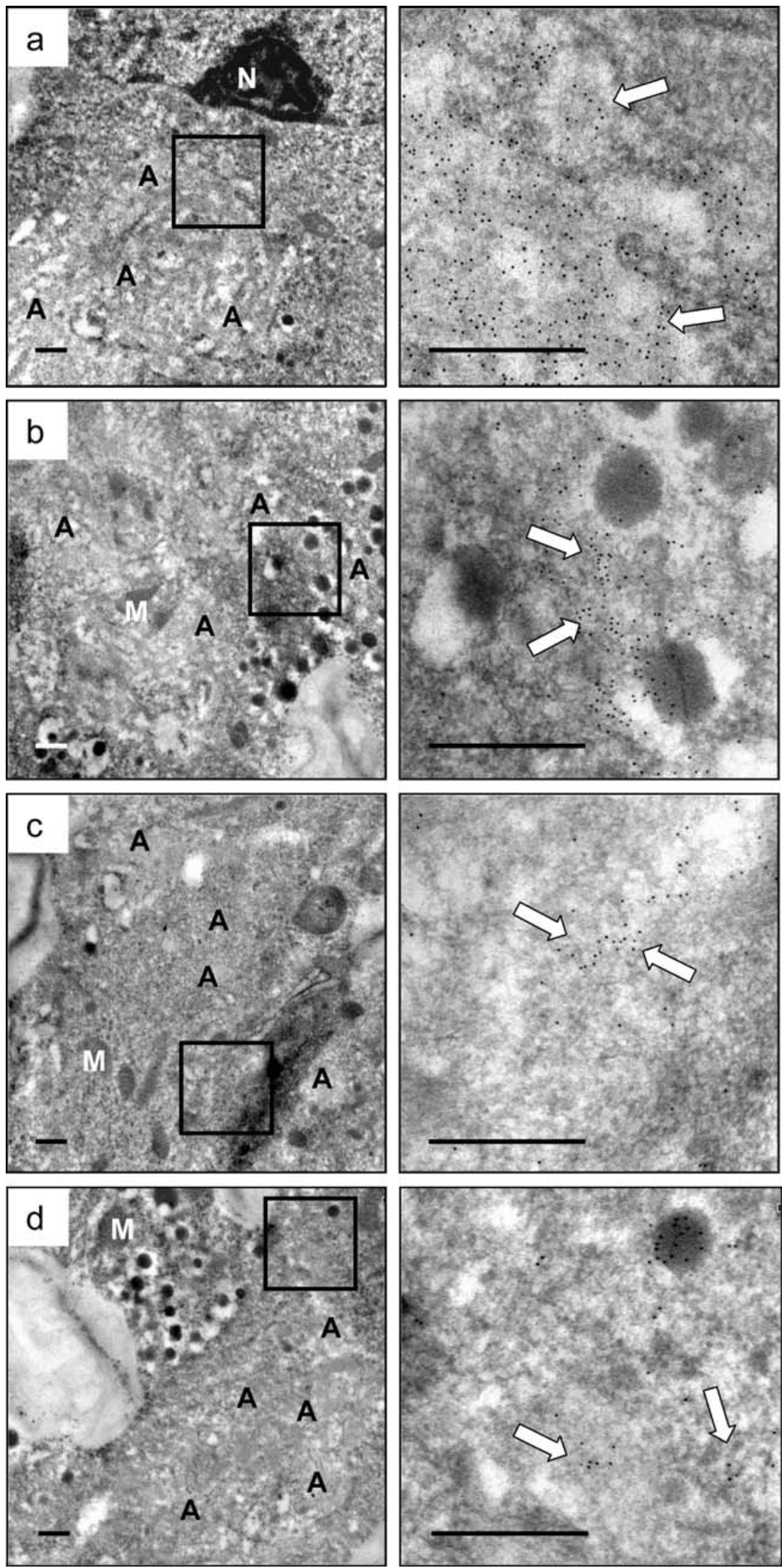
a

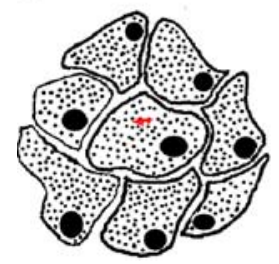

b

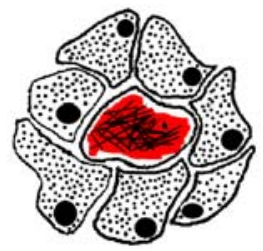

Fig. 8 Proposed sequence of events leading to islet amyloidosis. a First, the processing of proIAPP is affected by factors such as high levels of NEFAs or glucose. Granules with amyloid-like fibres fuse and form an intracellular proIAPP amyloid-like deposit. b Over time this aggregate enlarges and replaces most of the cell. $\mathbf{c}$ This cell dies and the amyloid becomes extracellular and can act as a template for

In particular, cells cultured in linoleic acid developed aberrant granule morphology. Intragranular fibrils have also been reported in islets cultured at high glucose concentrations [35]. These fibrils may represent the start of IAPP fibrillogenesis, and it is also possible that granules with fibrils may be released at exocytosis. Importantly, fibrils consisting of proIAPP efficiently seed fibril formation from fully processed IAPP (unpublished results).

Using several antibodies specific for different epitopes of the proIAPP molecule we were able to show proIAPP immunoreactivity in the amyloid-like intragranular fibrils and that these fibrils had the morphological characteristics of classical amyloid fibrils. The finding of intragranular fibrils containing proIAPP is interesting. Knight and Miranker showed that the rate of amyloid formation was strongly enhanced when IAPP and phospholipid bilayers were incubated together, and that fibril formation and elongation occurred from the surface of the lipid bilayer [36]. Furthermore, these authors suggested that beta cells exposed to hyperlipidaemia remodulate their membranes by increasing the negative charge. In a recent study, addition of negatively charged phosphatidylserine, a phospholipid component of cellular membranes, accelerated aggregation kinetics of synthetic human IAPP [37]. Considering that proIAPP has a theoretical $\mathrm{p} I$ value of 9.51, while that of IAPP is 8.90 , proIAPP would be more efficiently attracted to anionic cellular membranes and form fibrils at this site. Given its proximity to a lipid bilayer and its inefficient hormone precursor processing, the halo region of the beta cell granule might just be the perfect milieu for proIAPP fibrillogenesis. Insulin is known to inhibit fibril formation of IAPP in vitro, but nothing is known about the ability of proinsulin or insulin to interfere with amyloidogenesis of proIAPP [33, 38, 39].

The animals in this study probably had chronically high levels of NEFAs in their circulation since they became rapidly obese and continued to gain weight during the whole study. A high-fat diet is an essential factor for the development of amyloid in developed transgenic mouse strains $[26,40]$. How a high-fat diet can trigger amyloid deposition is not known. Furukawa et al. have reported that MIN6 cells incubated with chronic high levels of NEFAs

C

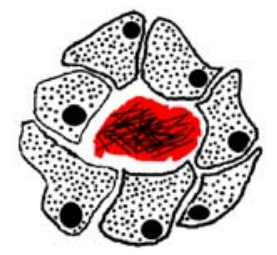

d

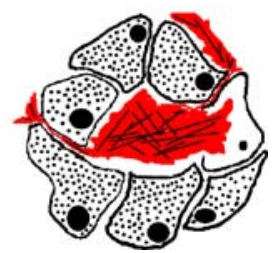

further amyloid formation. d Amyloid is now made up by IAPP secreted from neighbouring beta cells. Formation of extracellular amyloid fibrils is preceded by the formation of toxic intermediates, which can interact with the cell membrane of surrounding cells and cause ionic influx, triggering the apoptosis cascade

release elevated levels of proinsulin but do not express higher levels of proinsulin mRNA [17]. Levels of mRNA for $\mathrm{PC} 1 / 3$ and $\mathrm{PC} 2$ were not altered either; thus a deficiency in the activity of the prohormone convertases was proposed. A study on the effect of rosiglitazone and metformin on islet amyloid formation in transgenic mice fed a high-fat diet was recently conducted [41]. These two drugs increase insulin sensitivity and thereby reduce the secretory demands on beta cells. Though treatment with these drugs reduced amyloid mass, it did not prevent amyloid from being formed [41]. The authors concluded that beta cell lesions and amyloid deposition are not secondary to peripheral insulin resistance, but a direct effect of a high concentration of circulating lipids. NEFAs can act directly on the beta cells through the cell surface receptor GPR40 and enhance glucose-stimulated insulin secretion [42]. Lipid content in the circulation can negatively affect the beta cell in many ways, one of the most important being the alteration of prohormone processing.

In addition to intragranular fibrils, larger intracellular aggregates of amyloid-like material were also observed in beta cells of the +hIAPP/-mIAPP mice and the human islet grafts. These amyloid-like structures were denser than the intragranular fibrils. When immunolabelled with antisera specific for proIAPP (A169 and A165) and investigated in an electron microscope, the amyloid-like aggregates in the murine beta cells showed a strong and even labelling pattern. In amyloid in human islet implants, proIAPP reactivity was not as abundant and had a more patchy appearance. The reasons for these differences are unknown.

In conclusion, we propose that the initial step in the formation of islet amyloid is the intracellular aggregation of proIAPP. ProIAPP fibrils then act as seeds for further amyloidogenesis from mature IAPP. The proposed sequence of events is shown in Fig. 8.

Acknowledgements This work was supported by the Swedish Research Council, the Swedish Diabetes Association, the Family Ernfors Fund, Östergötland County Council and the Foundation in Memory of Lars Hierta. 


\section{References}

1. Westermark P, Wilander E, Westermark GT, Johnson KH (1987) Islet amyloid polypeptide-like immunoreactivity in the islet B cells of type 2 (non-insulin-dependent) diabetic and nondiabetic individuals. Diabetologia 30:887-892

2. Westermark P, Wernstedt C, Wilander E, Sletten K (1986) A novel peptide in the calcitonin gene related peptide family as an amyloid fibril protein in the endocrine pancreas. Biochem Biophys Res Commun 140:827-831

3. Sanke T, Bell GI, Sample C, Rubenstein AH, Steiner DF (1988) An islet amyloid peptide is derived from an 89-amino acid precursor by proteolytic processing. J Biol Chem 263: $17243-17246$

4. Badman MK, Shennan KI, Jermany JL, Docherty K, Clark A (1996) Processing of pro-islet amyloid polypeptide (proIAPP) by the prohormone convertase PC2. FEBS Lett 378:227-231

5. Higham CE, Hull RL, Lawrie L et al (2000) Processing of synthetic pro-islet amyloid polypeptide (proIAPP) 'amylin' by recombinant prohormone convertase enzymes, PC2 and PC 3 , in vitro. Eur J Biochem 267:4998-5004

6. Marzban L, Trigo-Gonzalez G, Zhu X et al (2004) Role of betacell prohormone convertase (PC) $1 / 3$ in processing of pro-islet amyloid polypeptide. Diabetes 53:141-148

7. Docherty K, Hutton JC (1983) Carboxypeptidase activity in the insulin secretory granule. FEBS Lett 162:137-141

8. Marzban L, Soukhatcheva G, Verchere C (2005) Role of carboxypeptidase $\mathrm{E}$ in processing of pro-islet amyloid polypeptide in beta-cells. Endocrinology 146:1808-1817

9. Milgram S, Kho S, Martin G, Mains R, Eipper B (1997) Localization of integral membrane peptidylglycine alphaamidating monooxygenase in neuroendocrine cells. J Cell Sci 110:695-706

10. Roberts AN, Leighton B, Todd JA et al (1989) Molecular and functional characterization of amylin, a peptide associated with type 2 diabetes mellitus. Proc Natl Acad Sci USA 86: 9662-9666

11. Lukinius A, Wilander E, Westermark GT, Engstrom U, Westermark P (1989) Co-localization of islet amyloid polypeptide and insulin in the B cell secretory granules of the human pancreatic islets. Diabetologia 32:240-244

12. Smeekens SP, Montag AG, Thomas G et al (1992) Proinsulin processing by the subtilisin-related proprotein convertases furin, PC2, and PC3. Proc Natl Acad Sci USA 89:8822-8826

13. Block MB, Mako M, Steiner DF, Rubenstein AH (1971) Elevated circulating proinsulin levels in insulin-requiring diabetic patients. J Lab Clin Med 78:811-812

14. Kahn SE, Leonetti DL, Prigeon RL, Boyko EJ, Bergstrom RW, Fujimoto WY (1995) Proinsulin as a marker for the development of NIDDM in Japanese-American men. Diabetes 44: 173-179

15. Seaquist ER, Kahn SE, Clark PM, Hales CN, Porte D Jr, Robertson RP (1996) Hyperproinsulinemia is associated with increased beta cell demand after hemipancreatectomy in humans. J Clin Invest 97:455-460

16. Kahn SE, Halban PA (1997) Release of incompletely processed proinsulin is the cause of the disproportionate proinsulinemia of NIDDM. Diabetes 46:1725-1732

17. Furukawa H, Carroll RJ, Swift HH, Steiner DF (1999) Longterm elevation of free fatty acids leads to delayed processing of proinsulin and prohormone convertases 2 and 3 in the pancreatic beta-cell line MIN6. Diabetes 48:1395-1401

18. Kayed R, Head E, Thompson J et al (2003) Common structure of soluble amyloid oligomers implies common mechanism of pathogenesis. Science 300:486-489

19. Lorenzo A, Razzaboni B, Weir G, Yankner B (1994) Pancreatic islet cell toxicity of amylin associated with type-2 diabetes mellitus. Nature 368:756-760

20. Janson J, Ashley R, Harrison D, McIntyre S, Butler P (1999) The mechanism of islet amyloid polypeptide toxicity is membrane disruption by intermediate-sized toxic amyloid particles. Diabetes 48:491-498
21. Anguiano M, Nowak R, Lansbury PJ (2002) Protofibrillar islet amyloid polypeptide permeabilizes synthetic vesicles by a porelike mechanism that may be relevant to type II diabetes. Biochemistry 41:11338-11343

22. Sparr E, Engel M, Sakharov D et al (2004) Islet amyloid polypeptide-induced membrane leakage involves uptake of lipids by forming amyloid fibers. FEBS Lett 577:117-120

23. Paulsson JF, Westermark GT (2005) Aberrant processing of human proislet amyloid polypeptide results in increased amyloid formation. Diabetes 54:2117-2125

24. O'Brien TD, Butler AE, Roche PC, Johnson KH, Butler PC (1994) Islet amyloid polypeptide in human insulinomas. Evidence for intracellular amyloidogenesis. Diabetes 43:329-336

25. Westermark GT, Westermark P, Nordin A, Tornelius E, Andersson A (2003) Formation of amyloid in human pancreatic islets transplanted to the liver and spleen of nude mice. Ups J Med Sci 108:193-203

26. Westermark G, Gebre-Medhin S, Steiner DF, Westermark P (2000) Islet amyloid development in a mouse strain lacking endogenous islet amyloid polypeptide (IAPP) but expressing human IAPP. Mol Med 6:998-1007

27. Couce M, Kane LA, O'Brien TD et al (1996) Treatment with growth hormone and dexamethasone in mice transgenic for human islet amyloid polypeptide causes islet amyloidosis and beta-cell dysfunction. Diabetes 45:1094-1101

28. Janson J, Soeller W, Roche P et al (1996) Spontaneous diabetes mellitus in transgenic mice expressing human islet amyloid polypeptide. Proc Natl Acad Sci USA 93:7283-7288

29. Westermark P, Eizirik DL, Pipeleers DG, Hellerstrom C, Andersson A (1995) Rapid deposition of amyloid in human islets transplanted into nude mice. Diabetologia 38:543-549

30. Westermark G, Westermark P, Eizirik DL et al (1999) Differences in amyloid deposition in islets of transgenic mice expressing human islet amyloid polypeptide versus human islets implanted into nude mice. Metabolism 48:448-454

31. Puchtler H, Sweat F (1965) Congo red as a stain for fluorescence microscopy of amyloid. J Histochem Cytochem 13:693-694

32. Westermark P, Benson M, Buxbaum J et al (2002) Amyloid fibril protein nomenclature-2002. Amyloid 9:197-200

33. Westermark P, Li ZC, Westermark GT, Leckstrom A, Steiner DF (1996) Effects of beta cell granule components on human islet amyloid polypeptide fibril formation. FEBS Lett 379:203-206

34. Ma Z, Westermark GT (2002) Effects of free fatty acid on polymerization of islet amyloid polypeptide (IAPP) in vitro and on amyloid fibril formation in cultivated isolated islets of transgenic mice overexpressing human IAPP. Mol Med 8: 863-868

35. MacArthur DL, de Koning EJ, Verbeek JS, Morris JF, Clark A (1999) Amyloid fibril formation is progressive and correlates with beta-cell secretion in transgenic mouse isolated islets. Diabetologia 42:219-227

36. Knight JD, Miranker AD (2004) Phospholipid catalysis of diabetic amyloid assembly. J Mol Biol 341:1175-1187

37. Jayasinghe SA, Langen R (2005) Lipid membranes modulate the structure of islet amyloid polypeptide. Biochemistry 44:12113-12119

38. Janciauskiene S, Eriksson S, Carlemalm E, Ahren B (1997) B cell granule peptides affect human islet amyloid polypeptide (IAPP) fibril formation in vitro. Biochem Biophys Res Commun 236:580-585

39. Jaikaran E, Nilsson M, Clark A (2004) Pancreatic beta-cell granule peptides form heteromolecular complexes which inhibit islet amyloid polypeptide fibril formation. Biochem J 377: 709-716

40. Verchere CB, D'Alessio DA, Palmiter RD et al (1996) Islet amyloid formation associated with hyperglycemia in transgenic mice with pancreatic beta cell expression of human islet amyloid polypeptide. Proc Natl Acad Sci USA 93:3492-3496

41. Hull RL, Shen ZP, Watts MR et al (2005) Long-term treatment with rosiglitazone and metformin reduces the extent of, but does not prevent, islet amyloid deposition in mice expressing the gene for human islet amyloid polypeptide. Diabetes 54:2235-2244

42. Itoh Y, Kawamata Y, Harada M et al (2003) Free fatty acids regulate insulin secretion from pancreatic beta cells through GPR40. Nature 422:173-176 